donors among the American Red Cross donor population were $0.208 \%$ and $0.077 \%$ respectively ${ }^{6}$-that is, that the prevalence of $\mathrm{HBsAg}$ in repeat donors was $37 \%$ of the value found in first time donors.

The chief purpose of screening for HBsAg is not to identify blood donors positive for $\mathrm{HBsAg}$ but to reduce hepatitis $\mathrm{B}$ associated with transfusion. Thus the profit to be gained from screening depends not only on the number of donors positive for HBsAg who are identified but also on the infectivity of blood from these donors. As most donors in Denmark who are positive for $\mathrm{HBsAg}$ are healthy carriers of $\mathrm{HBsAg}$ the profit depends mostly on the infectivity in the healthy carrier state. The predominant opinion has been that the presence of $\mathrm{HBeAg}$ indicates active viral replication, so that material positive for $\mathrm{HBeAg}$ is highly infectious whereas material negative for $\mathrm{HBeAg}$ and positive for anti-HBe is non-infectious or carries an extremely low risk of infection. The expected outcome of receiving blood from a healthy carrier of $\mathrm{HBsAg}$ should therefore be immunisation against hepatitis $B$ virus. This study showed, however, that four out of seven recipients susceptible to infection with hepatitis B virus developed acute hepatitis B after receiving blood from a healthy carrier of HBsAg. Thus we conclude that healthy carriers of $\mathrm{HBsAg}$ are highly infectious as blood donors, probably because of the large amount of material transmitted. The system based on the presence of $\mathrm{HBeAg}$ and anti-HBe seems to be of no value in predicting the outcome in recipients of blood positive for $\mathrm{HBsAg}$.

The blood banks that participated in this study were: Rigshospitalet, Koebenhavns Kommunehospital, Bispebjerg Hospital, Hvidovre Hospital, Frederiksberg Hospital, KAS Gentofte, KAS Glostrup, and Storkoebenhavns Frivillige Bloddonorkorps.

We thank Lise Nielsen and Bente Iversen for technical help and Annette Fentz for help in preparing the manuscript.

\section{References}

1 Dodd RY. Hepatitis B (surface) antigen testing by radioimmunoassay. Am 7 Clin Pathol i975;63:847-5

Koretz RL, Gitnick GL. Prevention of post-transfusion hepatitis. Am $\mathcal{F}$ Med $1975 ; 59: 754-60$

Alter HJ, Holland PV, Morrow AG, Purcell RH, Feinstone SM, Moritsugu Y. Clinical and serological analysis of transfusion-associated hepatitis. Lance $975 ;$;i : $838-41$.

Reinicke Vybkjaer E, Poulsen H, Banke O, Lylloff K, Nordenfelt E. A study of reference to liver histology. N Engl f Med 1972;286:867-70.

5 Szmuness W, Prince AM, Brotman B, Hirsch RL. Hepatitis $B$ antigen and antibody in blood donors: an epidemiologic study. F Infect Dis 1973;127:17-25.

6 Bastiaans MJS, Dodd RY, Nath N, Pineda-Tamondong G, Sandler SG, Barker LF. Hepatitis-associated markers in the American Red Cross volunteer blood dono population. Vox Sang 1980;39:1-8.

(Accepted 4 fune 1985)

\title{
Screening for antimalarial maculopathy in rheumatology clinics
}

\author{
B W FLECK, A L BELL, J D MITCHELL, B J THOMSON, N P HURST, G NUKI
}

\begin{abstract}
Ophthalmoscopy and three tests of visual function were undertaken in 39 patients with rheumatoid arthritis receiving treatment with antimalarial drugs and in a control group of 16 patients with rheumatoid arthritis who were not receiving such treatment. Visual contrast sensitivity, macular threshold to red light, and central visual fields to red targets were not significantly different in treated patients and controls. There were no abnormalities in visual acuity, but 11 of 76 eyes of treated patients showed minor macular abnormalities on ophthalmoscopy that were not seen in control patients, suggesting that ophthalmoscopy may be the most sensitive measure of early drug toxicity. Five rheumatologists were able to identify 52 of 65 minor changes detected by an ophthalmologist.

These studies, and a critical review of published reports, suggest that in clinical practice antimalarial drugs can be administered safely to patients with
\end{abstract}

Princess Alexandra Eye Pavilion, Royal Infirmary, Edinburgh B W FLECK, MB, FRCSED, registrar

\section{Northern General Hospital, Edinburgh EH5 2DQ}

A L BELL, MD, MRCP, research fellow, rheumatic diseases unit

J D MITCHELL, MB, MRCP, temporary senior lecturer, department of medical neurology

B J THOMSON, MB, MRCP, registrar, rheumatic diseases unit

N P HURST, PHD, MRCP, senior registrar, rheumatic diseases unit

G NUKI, MB, FRCP, professor of rheumatology

Correspondence to: Professor Nuki. rheumatoid arthritis without the need for repetitive routine examination by an ophthalmologist or the use of complicated physiological tests. Recording of visual acuity in each eye and ophthalmoscopy by the prescribing doctor may be all that are required to detect early antimalarial maculopathy.

\section{Introduction}

In the 1960s several reports of corneal deposits and macular damage in patients with rheumatoid arthritis and systemic lupus erythematosus receiving treatment with antimalarial drugs led to the recommendation that all such patients should be regularly examined by an ophthalmologist. ${ }^{1}$ The need to continue this practice must be critically reassessed in the light of clinical experience with low dose treatment.

A review in 1982 of published reports showed only 13 cases of maculopathy with reduced visual acuity in patients taking chloroquine phosphate $250 \mathrm{mg}$ daily, or less, over a period of two to 10 years. ${ }^{2}$ Only four of 99 patients treated with hydroxychloroquine sulphate $\mathbf{4 0 0} \mathrm{mg}$ daily, or less, had any evidence of retinal toxicity when followed up prospectively for one to eight years, none developed visual loss, and all abnormalities were completely reversible after the treatment was stopped. ${ }^{3}$ A recent survey carried out in Cleveland, Ohio, showed no cases of maculopathy in 400 patients taking chloroquine phosphate $4 \mathrm{mg} / \mathrm{kg} /$ day or hydroxychloroquine $6.5 \mathrm{mg} / \mathrm{kg} /$ day over a mean period of seven years. ${ }^{4}$ Although comprehensive ophthalmological testing was a feature of each of these studies, the low risks of ocular toxicity with current regimens of antimalarial drug treatment suggest that routine surveillance by ophthalmologists may no longer be necessary.

In this study we compared the value of two standard tests of 
visual function-namely, central visual field testing with red targets and macular threshold to red light-with the newer technique of measurement of visual contrast sensitivity and ophthalmoscopy. We also assessed the ability of rheumatologists to detect minor ophthalmoscopic abnormalities in patients attending an arthritis clinic.

\section{Patients and methods}

Thirty nine patients with classical or definite rheumatoid arthritis ${ }^{5}$ taking antimalarial drugs were studied. A smaller group of 16 patients with rheumatoid arthritis who had not previously been exposed to antimalarial drugs was drawn from the same clinic. Activity of the disease was similar in patients receiving antimalarial treatment and control patients, although duration of disease was longer in those taking antimalarial drugs (table I). Twelve control patients were about to start treatment with slow acting suppressive antirheumatic agents after the failure of non-steroidal anti-inflammatory drugs to control their symptoms, and two others were already taking alternative second line drugs (one penicillamine and one oral gold).

Each patient was examined by a rheumatologist to confirm the diagnosis and record a drug history. Patients were then examined by an ophthalmologist for refraction and measurement of Snellen visual acuity. Screening for congenital colour blindness was performed with Ishihara pseudoisochromatic plates (numbers 1, 2, 6, 10, 14, and 18). Patients with congenital colour blindness, cataracts, or glaucoma were excluded. The following tests were then performed with optimal refractive correction: all patients underwent visual contrast sensitivity testing, while smaller subgroups underwent macular threshold to red light testing (28 antimalarial treated patients and 14 control patients) and central visual field to red targets testing (29 antimalarial treated patients and 10 control patients). These subgroups were representative of the whole group (tables I and II).

A Friedmann visual field analyser (mark I), incorporating a Kodak Wratten No 29 red filter, was used to test central visual field to red targets. The macular threshold for each eye was found, and the central field (within 10 degrees of fixation) was studied at this illumination setting. The Friedmann analyser has 14 points within 10 degrees of fixation, and inability to perceive any of these points, on a repeatable basis, was considered to be abnormal.

Macular threshold to red light was measured with an array of diodes emitting red light, the luminosity of which could be varied by pulse width modulation, from 0 to $1.35 \mathrm{~cd} / \mathrm{m}^{2}$. The test was performed at $2 \mathrm{~m}$, at which distance the array subtended two degrees of the visual angle. Background illumination was kept as constant as possible, at $0.01 \mathrm{~cd} / \mathrm{m}^{2}$. Patients were allowed to adapt to this level of illumination for roughly five minutes before the test was performed. Starting at a low level, luminosity was increased steadily until the patient could just perceive the red target on a repeatable basis. This luminosity was taken as the macular threshold to red light.

To determine visual contrast sensitivity a sinewave grating generator (10L-T221, SC Electronics) was used to produce vertical sinusoidal gratings on an oscilloscope. The contrast threshold of detection by the patient was recorded for a range of spatial frequencies.

Maculae were examined by a single ophthalmologist, who was unaware of the drug history or performance in the subjective tests, by direct ophthalmoscopy after dilatation of the pupils. Uniformity of pigmentation at the macula was scored using the following eight point scale: grade 1, uniform colouring of macula and intact foveolar reflex; grade 2, uniform colouring of macula and absent foveolar reflex; grade $3, \leqslant$ five drusen (small yellowish degenerative plaques) in macular area; grade 4, borderline fine granular depigmentation; grade 5, definite fine granular depigmentation; grade 6, "stippling" (fine granular hyperpigmentation and depigmentation); grade 7, "mottling" (coarse granular hyperpigmentation and depigmentation); grade 8, spots or area of disturbance of pigment at macula. Grades 1-6 are commonly seen changes that are related to age. Grades 7 and 8 were arbitrarily defined as being abnormal, in accord with previous descriptions of macular appearances in patients receiving antimalarial drug treatment. ${ }^{26}>$ Pigmentary changes of this type may occasionally regress when antimalarial drug treatment is stopped ${ }^{6} 7$ and are rarely seen as spontaneous degenerative changes in the age group under study. ${ }^{8}$

To assess the performance of rheumatologists in detecting ophthalmoscopic abnormalities of the macula five rheumatologists (two registrars, two senior registrars, and one consultant) examined 28 eyes of patients treated with antimalarial drugs, 13 of which were defined as abnormal. Their findings were compared with those of an ophthalmologist.

As findings in each eye are not independent variables when considering effects induced by drugs in a patient statistical analysis was undertaken after random allocation of one eye from each patient. Significance was assessed by the unpaired Student's $t$ test and the $\chi^{2}$ test.

\section{Results}

Table I gives details of patients' age, sex, and duration of disease, and table II gives details of drug treatment.

One patient, with senile macular degeneration, had a Snellen visual acuity of $6 / 9$ in each eye before starting antimalarial treatment. Visual acuity was $6 / 6$ or better in all other eyes examined.

TABLE I-Patients' age, sex, and duration of disease

\begin{tabular}{|c|c|c|c|c|c|}
\hline & No of patients & No of eyes examined & Mean (range) age (years) & Men:women & $\begin{array}{c}\text { Mean (range) duration of } \\
\text { disease (years) }\end{array}$ \\
\hline \multicolumn{6}{|c|}{ Treated with antimalarial drugs } \\
\hline $\begin{array}{l}\text { Total group } \\
\text { Macular threshold to red light subgroup } \\
\text { Red field subgroup }\end{array}$ & $\begin{array}{l}39 \\
28 \\
29\end{array}$ & $\begin{array}{l}76^{*} \\
54^{*} \\
56^{*}\end{array}$ & $\begin{array}{l}52 \cdot 5(23-68) \\
51 \cdot 9(25-73) \\
52 \cdot 2(25-73)\end{array}$ & $\begin{array}{l}9: 30 \\
9: 19 \\
8: 21\end{array}$ & $\begin{array}{l}9 \cdot 3(1 \cdot 5-35) \\
8 \cdot 5(1 \cdot 5-35) \\
8 \cdot 5(1 \cdot 5-35)\end{array}$ \\
\hline \multicolumn{6}{|c|}{ Control patients } \\
\hline $\begin{array}{l}\text { Total group } \\
\text { Macular threshold to red light subgroup } \\
\text { Red field subgroup }\end{array}$ & $\begin{array}{l}16 \\
14 \\
10\end{array}$ & $\begin{array}{l}32 \\
28 \\
20\end{array}$ & $\begin{array}{l}48 \cdot 3(23-73) \\
48 \cdot 9(23-73) \\
49 \cdot 5(23-73)\end{array}$ & $\begin{array}{l}7: 9 \\
7: 7 \\
5: 5\end{array}$ & $\begin{array}{l}3 \cdot 8(1 \cdot 5-10) \\
4 \cdot 0(1 \cdot 5-10) \\
4 \cdot 1 \quad(2-10)\end{array}$ \\
\hline
\end{tabular}

* Two patients had only one eye included in the study, the other eye having incidental abnormalities (one amblyopia and one previous trauma).

\begin{tabular}{|c|c|c|c|c|}
\hline & No of patients & Mean (range) daily dose (mg)* & Mean (range) total dose (g) & $\begin{array}{l}\text { Mean (range) duration of } \\
\text { treatment (months) }\end{array}$ \\
\hline \multicolumn{5}{|c|}{ Treated with chloroquine phosphate } \\
\hline $\begin{array}{l}\text { Total group } \\
\text { Macular threshold to red light subgroup } \\
\text { Red field subgroup }\end{array}$ & $\begin{array}{l}19 \\
13 \\
12\end{array}$ & $\begin{array}{l}210 \cdot 9(125-250) \\
216 \cdot 5(125-250) \\
218.9(125-250)\end{array}$ & $\begin{array}{l}302 \cdot 1(46-912) \\
345 \cdot 9(60-912) \\
351 \cdot 2(60-912)\end{array}$ & $\begin{array}{l}45 \cdot 1(8-120) \\
51 \cdot 1(8-120) \\
50 \cdot 7(8-120)\end{array}$ \\
\hline \multicolumn{5}{|c|}{ Treated with hydroxychloroquine } \\
\hline $\begin{array}{l}\text { Total group } \\
\text { Macular threshold to red light subgroup } \\
\text { Red field subgroup }\end{array}$ & $\begin{array}{l}20 \\
15 \\
17\end{array}$ & $\begin{array}{l}369 \cdot 4(200-488) \\
372 \cdot 5(200-488) \\
364 \cdot 0(200-488)\end{array}$ & $\begin{array}{l}146 \cdot 9(60-438) \\
129 \cdot 1(60-219) \\
130 \cdot 9(60-219)\end{array}$ & $\begin{array}{l}14 \cdot 4(5-36) \\
12 \cdot 8(5-24) \\
13 \cdot 4(5-24)\end{array}$ \\
\hline
\end{tabular}

*Total dose (mg)/duration of treatment (days). 
No abnormalities in macular appearance were detected in the control group. In the antimalarial treated group 11 maculae (in six patients) were abnormal: three were grade 7 and eight grade 8 .

The mean (SD) macular threshold to red light of the antimalarial treated group was $4.61(2.62) \times 10^{-2} \mathrm{~cd} / \mathrm{m}^{2}$ and of the control group $4.80(2.34) \times 10^{-2} \mathrm{~cd} / \mathrm{m}^{2}$. The figure shows the results of contrast sensitivity testing. No significant differences in macular threshold to

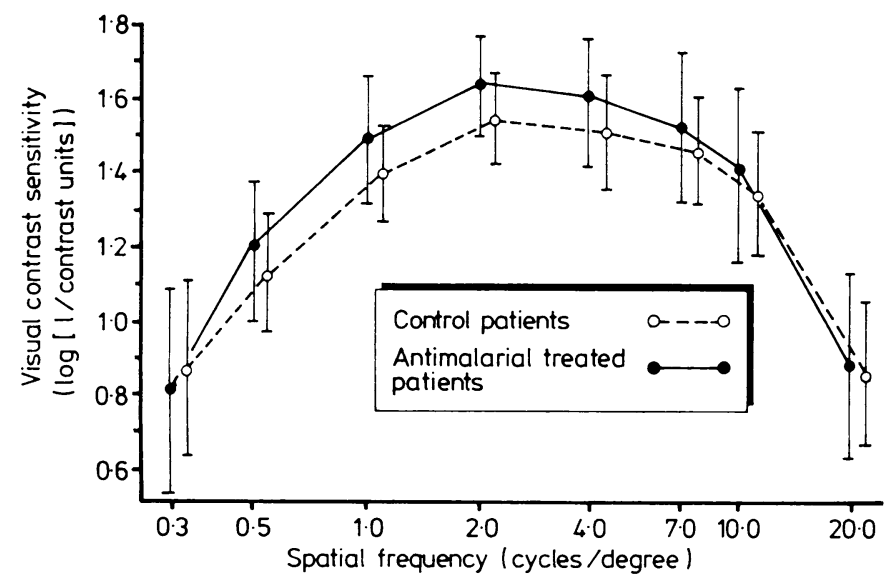

Visual contrast sensitivity as a function of spatial frequency in antimalarial treated and control patients.

red light or visual contrast sensitivity were seen at any spatial frequency between antimalarial treated patients and control patients. Macular abnormalities on ophthalmoscopy were not associated with abnormalities of macular threshold to red light or visual contrast sensitivity.

Central visual fields to red targets were measured in 29 antimalarial treated patients (58 eyes) and 10 control patients (20 eyes). The macular threshold was found to lie within the range $4.7-7.4 \times 10^{-2}$ $\mathrm{cd} / \mathrm{m}^{2} / \mathrm{s}$ (setting $2 \cdot 0-1 \cdot 8$ on Friedmann analyser) in every eye tested, and visual field testing was performed at this setting. Fourteen eyes $(25 \%)$ of antimalarial treated subjects and four eyes $(20 \%)$ of control subjects showed abnormalities $\left(\chi^{2}=0.07, \mathrm{NS}\right)$.

Within the antimalarial treated group abnormalities ranged from an inability to see one of the 14 points tested to an inability to see 10 of them. Of 11 maculae that appeared abnormal, only four had abnormal red fields. Thirty five of the 45 maculae that appeared normal had a normal red field.

Of a total of 140 macular examinations, 119 were correctly assessed by the rheumatologists. In eight cases a normal macula was labelled falsely as abnormal. The rheumatologists failed to recognise macular abnormalities identified by the ophthalmologist in only 13 of 65 ophthalmoscopic examinations. On 11 of these occasions the unrecognised macula was grade 7 and on two occasions grade 8 . On these two occasions the missed abnormality was in a patient with unilateral abnormality: one macula was within normal limits and the other showed grade 8 abnormality.

\section{Discussion}

The risk of maculopathy and the apparent need for regular examination by an ophthalmologist are major considerations inhibiting the wider use of antimalarial drugs in rheumatological practice. By the time visual acuity has become impaired irreversible changes will have taken place. ${ }^{6} 9$ If macular changes can be detected ophthalmoscopically before this stage, however, the maculotoxic features may regress after withdrawal of the drug. ${ }^{61011}$ Clearly, it is desirable that antimalarial maculopathy be detected at this stage.

Previous studies in patients treated with antimalarial drugs have suggested that testing central visual fields with red targets may detect abnormal visual function before ophthalmoscopic abnormalities are detectable. ${ }^{612} 13$ Other studies have suggested that tests of macular threshold to red light may be abnormal when macular appearance is normal on ophthalmoscopy. ${ }^{14}{ }^{15} \mathrm{We}$ found that minor abnormalities in these tests occur as often in control patients as in treated patients, and this is also true of visual contrast sensitivity testing, which is valuable in detecting occult visual disturbance in glaucoma ${ }^{16}$ and demyelinating diseases, ${ }^{17}$ but which has not previously been used to try to detect early antimalarial maculopathy. Our findings show that careful ophthalmoscopic examination of the macula can be a sensitive index of retinal toxicity when visual acuity remains intact. Taken together with accumulating evidence that the risk of ocular toxicity leading to reduced visual acuity is remote in patients receiving low dose antimalarial drugs for the treatment of rheumatic diseases, ${ }^{2-4}$ these findings suggest that routine surveillance by ophthalmologists might no longer be necessary.

Our preliminary studies confirmed that, even without training, rheumatologists are able to identify $80 \%$ of all minor changes in macular appearance detected by an ophthalmologist. This suggests that regular ophthalmoscopy by the prescribing doctor may be all that is required to monitor patients with rheumatic diseases receiving antimalarial drugs.

As long term prospective studies in rheumatology outpatient clinics will be needed to test the safety of this hypothesis we have adopted the following policy: (a) Baseline assessment of visual acuity and ophthalmoscopic examination of maculae after dilatation of pupils before starting treatment with antimalarial drugs, thus reducing the possibility of confusing senile degenerative changes with changes induced by drug treatment at a later date. (b) Restriction of dose of antimalarial drug to chloroquine phosphate $250 \mathrm{mg}$ daily or hydroxychloroquine sulphate $200 \mathrm{mg}$ twice daily and half these doses for patients weighing less than $65 \mathrm{~kg}$. (c) Six monthly assessment of visual acuity and ophthalmoscopy after dilatation of pupils by doctors in rheumatology follow up clinics. (d) Secondary referral to an ophthalmologist with experience of antimalarial maculopathy if ophthalmoscopic abnormalities are detected or visual acuity is impaired.

The British National Formulary, a joint publication of the BMA and the Pharmaceutical Society of Great Britain, recommends ophthalmic examination of patients before starting treatment and at three to six month intervals if antimalarial drug treatment is prolonged beyond one year but does not specify the nature of the ophthalmic examination or who should undertake it. ${ }^{18}$ We share the opinion of the ethical committee of the BMA, quoted by the Faculty of Ophthalmologists, that "the responsibility for the decision as to the duration or continuation of treatment must lie with the practitioner who initiated the treatment, unless the responsibility for this has been specifically accepted by another practitioner." ${ }^{19}$ Our studies suggest that rheumatologists need to ask ophthalmologists to share this responsibility only in a minority of patients with rheumatic diseases receiving treatment with antimalarial drugs.

We thank Mr R P C Budden, of Ferranti, for help with the design and construction of the light emitting diode array for testing macular threshold to red light. We also thank Miss Joan Lennie for her help preparing and typing this manuscript.

\section{References}

1 Okun E, Gouras P, Bernstein H, Von Sallmann L. Chloroquine retinopathy. A report of 8 cases with electroretinogram and dark adaptation findings. Arch

2 Marks IS. Chloroquine retinopathy: is there a safe daily dose ? Ann Rheum Dis $1982 ; 41: 52-8$

Rynes RI. Ophthalmologic safety of long-term hydroxychloroquine sulphate

4 treatment. Am F Med 1983;75 (suppl 1A):35-9. with antimalarials. Am $\mathcal{Z}$ Med $1983 ; 75$ (Suppl 1A):40-5.

5 Ropes MW, Bennett GA, Cogg S, Jacox R, Jessar RA. 1958 revision of diagnostic criteria for rheumatoid arthritis. Arthritis Rheum 1959;2:16-20.

Brinkley JR, Dubois EL, Ryan SJ. Long term course of chloroquine retinopathy after cessation of medication. Am $\mathrm{f}$ Ophthalmol $1978 ; 88: 1-11$.

7 Mills PV, Beck M, Power BJ. Assessment of the retinal toxicity of hydroxychloroquine. Trans Ophthalmol Soc UK 1981;101:109-13.

8 Scherbel AL, Mackenzie AH, Housek JE, Atdjian M. Ocular lesions in rheumatoid arthritis and related disorders with particular reference to retinopathy. A 1965;273:360-6

9 Ogawa S, Kurumatani N, Shibaike N, Yamazoe S. Progression of retinopathy long after cessation of chloroquine therapy. Lancet $1979 ; \mathrm{i}: 1408$. 
10 Carr RE, Henkind P, Rothfield N, Siegel IM. Ocular toxicity of antimalarial drugs. Long-term follow-up. Am $\mathcal{F}$ Ophthalmol 1969;66:738-44.

(he early stages. Lance

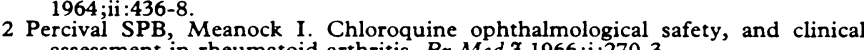
assessment in rheumatoid arthritis. Br Med $71966 ; \mathrm{i}: 270-3$.

obin DR, Krohel BG, Rynes RI. Hydroxychloroquine. Seven-year experience. Arch Ophthalmol 1982;100:81-3.

14 Friedmann AI. The early detection of chloroquine retinopathy with the Friedmann visual field analyser. Ophthalmologica $1969 ; 158$ (Suppl):583-91 15 Carr RE, Gouras P, Gunkel RD. Chloroquine retinopathy. Early detection by
retinal threshold tests. Arch Ophthalmol 1966;75:171-8.
16 Arden GB. Visual loss in patients with normal visual acuity. Trans Ophthalmol Soc UK 1978;98(2):219-231.

17 Zimmern RL CB(2):21l FW; Wilkinson IMS Subtle disturbances of vision after optic neuritis elicited by studying contrast sensitivity. $\mathcal{F}$ Neurol Neurosurg

18 Joint Formulary Committee of the British Medical Association and The Pharmaceutical Society of Great Britain. British National Formulary 1985. London: 1985:320

19 Faculty of Ophthalmologists. 37th annual report. London: Faculty of Ophthalmologists, 1981-2:12.

(Accepted 5 fuly 1984)

\section{SHORT REPORTS}

\section{Effect of seat belt legislation on the incidence of sternal fractures seen in the accident department}

In the United Kingdom legislation on the compulsory wearing of seat belts was introduced on 1 February 1983. Subsequently the number of front seat occupants of vehicles wearing seat belts increased dramatically. There is no doubt that seat belts correctly worn greatly reduce the incidence of serious and fatal injuries in automobile accidents, ${ }^{12}$ and in Cambridge a reduction of $20-25 \%$ has been seen since legislation.

Seat belts may, however, be associated with certain injuries ${ }^{3}$ for example, fractured sternums-and since legislation we might expect to see an increased incidence of these. ${ }^{45}$ At Addenbrooke's Hospital, Cambridge, I noticed that a comparatively large proportion of front seat car occupants hurt in automobile accidents were presenting with anterior chest pain and were found to have sternal fractures. The aim of this study was therefore to determine whether the incidence of patients presenting to the casualty department with a sternal fracture had increased as a result of seat belt legislation.

\section{Method and results}

The data were collected from the casualty records of Addenbrooke's Hospital (which sees about 40000 casualties a year). All patients seen in the casualty department for injuries received in automobile accidents are documented as such. During 1 February 1981 to 31 January 1983 and 1 February 1983 to 31 January 1985 -that is, the two years before and after legislation-all patients sustaining injuries as front seat occupants in automobile accidents were identified. Those who received chest injuries and also those who received multiple injuries where a chest injury was not specifically recorded had their records drawn. From these it was determined which patients had sustained a sternal fracture and whether or not they had been wearing a seat belt at the time of their accident.

Also included were patients brought into hospital dead as a result of an automobile accident and those admitted but who subsequently died of their injuries. From necropsy reports it was determined if any had sustained a sternal fracture (table).

Comparison of the two study periods showed a highly significant increase in the number of patients presenting with sternal fractures since legislation $\left(\chi^{2}=13.14 ; \mathrm{p}<0.001\right)$. About $90^{\circ}$ of these fractures occurred in patients claiming to have been wearing a seat belt at the time of their accident. By contrast, there was no significant change in the overall incidence of all chest injuries in the two periods $\left(\chi^{2}=0.21 ; \mathrm{p}>0.5\right)$. This last finding agrees with other studies. ${ }^{5}$

Numerical data on front seat occupants of vehicles admitted to casualty department after road traffic accidents during two years before and two years after introduction of compulsory wearing of seat belts (1 February 1983)

\begin{tabular}{lcc}
\hline & $\begin{array}{c}\text { February 1981 to } \\
\text { January } 1983\end{array}$ & $\begin{array}{c}\text { February 1983 to } \\
\text { January 1985 }\end{array}$ \\
\hline $\begin{array}{l}\text { No of patients seen in casualty } \\
\text { department after automobile }\end{array}$ & & \\
$\quad$ accidents & 1970 & 1620 \\
No with chest injuries & 226 & 178 \\
Fractured sternums: & & 24 \\
$\quad$ Total & 7 & 21 \\
$\quad$ Belted & 3 & 2 \\
$\quad$ Unbelted & 3 & 1 \\
$\quad$ Dnknown & 1 & 8 \\
$\quad$ Priver & 6 & 8 \\
$\quad$ Meanger age (range) & 1 & $58(34-84)$ \\
$\quad$ Male: female ratio & $39(18-61)$ & $2: 1$ \\
\hline
\end{tabular}

\section{Comment}

Before wearing seat belts became compulsory most sternal fractures were caused by the steering wheel or dashboard in unrestrained front seat occupants. Some people sustained fatal, multiple injuries and never reached the casualty department, having been certified dead at the accident site. These deaths accounted for about $5-10 \%$ of all deaths among front seat occupants (the latter totalling about 35 a year before legislation) and the proportion was similar in the period after legislation. Although the number of deaths before legislation was greater by about $20 \%$, probably the number of sternal fractures in these people was not greatly different between the two periods. Lack of information on this relatively small group would not alter the significance of the increase in sternal fractures seen since seat belt legislation.

My study shows a threefold increase in the incidence of sternal fractures since legislation, coupled with an increase in the number of people surviving high speed automobile accidents and also a pronounced increase in the number of people wearing seat belts. Most patients sustaining a sternal fracture while wearing a seat belt received no other serious injury and the fracture was uncomplicated.

Evidence to date confirms the great benefit of correctly worn seat belts in automobile accidents. It therefore seems reasonable to conclude that an uncomplicated fracture of the sternum, albeit painful, is an acceptable price for the compulsory wearing of seat belts in exchange for more serious multiple injuries or even death.

I thank the casualty department of Addenbrookes' Hospital for help in facilitating this study.

Mellbring G, Damlin S, Lindblad B. The hospital experience of seat-belt legislation in the county of Skaraborg, Sweden. Injury 1981;12:506-9.

cDermott FT, Hough DE. Effect of compulsory wearing of seat-beits. Br 7 Surg 1979;66:518-21.

3 Garrett JW, Braunstein PW. Seat-belt syndrome. F Trauma 1962;2:220-38.

4 Trinca GW, Dooley BJ. The effects of seat-belt legislation on road traffic injuries. Aust NZ $\mathcal{f}$ Surg 1977;47:150-5

Newman RJ, Jones IS. A prospective study of 413 consecutive car occupants with chest injuries. $\mathcal{F}$ Trauma $1984 ; 24: 129-35$.

(Accepted 24 fune 1985)

Addenbrooke's Hospital, Cambridge

JOHN S BUDD, BSC, MB, casualty officer

Correspondence to: Department of Thoracic Surgery, Frenchay Hospital, Bristol BS 16 1LE.

\section{Cyanide toxicity after immersion and the hazards of dicobalt edetate}

We report on a patient with cyanide toxicity who developed severe oedema after treatment with dicobalt edetate.

\section{Case report}

A 43 year old industrial chemist was admitted to casualty 15 minutes after total immersion for three minutes in a vat containing 1000 gallons $(4546$ litres) of hot cupric cyanide. On arrival he was deeply unconscious, cyanosed, and breathing irregularly. Oxygen $100 \%$ was administered by mask and intravenous infusion begun. His contaminated clothing was removed and the "cyanide box" in casualty opened. Arterial blood was obtained for measurement of gas tensions; cyanide, urea, electrolyte, and glucose concentrations; and full blood count. In accordance with the instructions he was given 300 